Jurnal ENGINE Vol.1 No.1, Mei 2017, pp 20-25

e-ISSN: 2579-7433

\title{
PENGARUH PADUAN SERBUK Fe12\% PADA ALUMINIUM TERHADAP POROSITAS DAN STRUKTUR MIKRO DENGAN METODE GRAVITY CASTING
}

\author{
Sumpena \\ Prodi Teknik Mesin Universitas Proklamasi 45 Yogyakarta \\ ${ }^{(1)}$ Email: sumpenast@yahoo.co.id \\ Jl. Proklamasi No.1 Babarsari, Depok, Sleman, Yogyakarta
}

\begin{abstract}
The purpose of this research is to know the effect of Fe12\% powder alloy on aluminum to porosity and micro structure by gravity casting method. Metal Matrix Composite (MMC) is an engineering material formed from the combination of two or more materials to obtain new materials with better properties. Making of composite material with aluminum matrix or metal matrix composite $(M M C)$ can be done by casting method. The composite forming elements are called boosters (fibers or particles) and binders (matrices). In the process of casting metal can occur porosity In the casting process with sand molds usually occur porosity, causing the mechanical properties of casting objects decreased. Porosity is caused by bubbles of gas, gas released by the core when exposed to metal liquid heat, resulting in pores or perforated defects.The process of smelting was carried out at the metal foundry laboratory of Mechanical Engineering UP 45 Yogyakarta. The smelting process uses a krusible furnace with coke fuel, on which it is placed kowi to place aluminum and iron powder to be melted. Aluminum and $12 \%$ iron powder are weighed in accordance with the volume of the pattern, so that the melt does not suffer from metal deficiency. Observation of porosity is done by looking visually on each side of the outer part of the casting object. Observation of microstructure using optical microscope is done by taking three samples of specimen castings that have been in the preparation of polishing machine and etching. The effect of Fe $12 \%$ alloys on porosity is the average porosity occurring on specimens $A, B$ and $C$ of $2,766 \mathrm{gr} / \mathrm{cm} 3$. The effect of Fe $12 \%$ alloys on micro structure is the spreading of Fe, Si and Mg elements evenly, but for the C specimens of Fe and Si bersenyawa, while the Al and $\mathrm{Mg}$ elements are separate.
\end{abstract}

Keywords: AlFe12\% Alloy, Casting, Porosity and Micro Structure

\section{PENDAHULUAN}

Pengecoran logam merupakan salah satu metode dalam pembuatan suatu benda. Metode dalam pengecoran logam berkembang menjadi berbagai macam jenis seiring dengan berjalannya waktu, perkembangan ilmu pengetahuan dan meningkatnya kebutuhan manusia. Metode pengecoran ditinjau dari jenis cetakannya dapat digolongkan menjadi metode pengecoran logam cetakan tetap dan tidak tetap. Metode pengecoran logam cetakan tetap diantaranya metode high pressure die casting, low pressure die casting, pengecoran sentrifugal dan gravity die casting, sedangkan metode pengecoran cetakan tidak tetap diantaranya pengecoran cetakan pasir, investment casting dan lost foam casting (Tata Surdia, 2006).

Pembuatan material komposit dengan matrik aluminium atau disebut metal matrix composite (MMC) bisa dilakukan dengan metode casting. Komposit adalah struktur material yang terdiri dari kombinasi dua bahan atau lebih, yang dibentuk dalam skala makroskopik dan menyatu secara fisik. Unsur - unsur pembentuk komposit disebut penguat (serat atau partikel) dan pengikat (matrik). Matrik berfungsi untuk mengisi ruang dalam komposit, mengikat serat agar tetap pada posisinya, mentransfer tegangan ke serat, menjaga permukaan serat dari pengikisan dan menjaga serat dari pengaruh lingkungan luar. Metal Matrix Composite (MMC) merupakan bahan teknik yang dibentuk dari kombinasi dua atau lebih bahan, untuk mendapatkan material baru dengan sifat yang lebih baik.

MMC sedikitnya terdiri dari dua komponen, yaitu matrik logam dan penguat dalam bentuk serbuk, palet, whisker, serat pendek atau serat kontinyu. Jika dibandingkan dengan logam tunggal, MMC mempunyai keunggulan, yaitu: kekuatan spesifik lebih tinggi, ketahanan aus lebih baik, ekspansi termal rendah dan konduktivitas termal baik. MMC juga memiliki unjuk kerja pada temperatur tinggi lebih baik dibanding dengan komposit dengan matrik polimer. Sifat 
Jurnal ENGINE Vol.1 No.1, Mei 2017, pp 20-25

e-ISSN: 2579-7433

mekanis logam aluminium dapat ditingkatkan dengan proses presipitasi atau dengan menambahkan penguat. Penguat yang ditambahkan dapat berupa serat kontinyu, serat pendek, whisker atau partikulat (Sulardjaka, dkk. 2012).

Pada proses pengecoran logam, benda hasil coran sering timbul adanya porositas. Porositas hal yang tidak diinginkan terjadi pada produk benda coran karena menyebabkan sifat mekanik coran menurun. Interaksi antara logam dan cetakan dapat mengakibatkan porositas di bawah permukaan aluminium yang dituang dengan cetakan pasir. Gelembunggelembung gas (bubbles) yang terbentuk dicelah cetakan saat kontak dengan logam dan gelembung di dalam logam cair yang terperangkap pada saat dingin akan menjadi pori-pori di dalam benda cor. Porositas juga dapat disebabkan dari gas yang dikeluarkan oleh inti saat terkena panas cairan. Gas ini terperangkap dalam cairan dan setelah dingin akan menjadi cacat lubang pada benda sebagaimana disajikan pada Gambar 2.5. Hidro karbon dapat terurai pada permukaan logam cair dan melepaskan hidrogen. Permukaan cairan tidak kekurangan hidrogen dan sebagian besar hidrogen akan terkonveksi ke atmosfer bebas, namun sebagian akan terdifusi ke logam cair jika tidak dicegah. Jika terdifusi ke logam cair dan ikut membeku di dalamnya maka akan menjadi cacat pori-pori pada benda tersebut (Campbell, 2003).

Sedangkan densitas merupakan ukuran kerapatan suatu zat yang dinyatakan banyaknya zat (massa) per satuan volume. Jadi satuannya adalah satuan massa per satuan volume, misalnya $\mathrm{kg}$ per meter kubik atau gram per centimeter kubik.

keterangan:

$$
\rho=\mathrm{m} / \mathrm{v}
$$

$\boldsymbol{\rho}=$ densitas $/$ massa jenis $\left(\mathrm{gr} / \mathrm{cm}^{3}\right)$

$\mathrm{m}=$ massa $(\mathrm{gr})$

$\mathrm{v}=$ volume $\left(\mathrm{cm}^{3}\right)$

Ini digunakan untuk menentukan tingkat porositas dari benda coran.
Penelitian MMC telah dilakukan oleh Sulardjaka, D.B. dkk, (2012) dengan judul pengaruh temperatur tuang pada proses pengecoran stir casting terhadap densitas dan porositas komposit aluminium diperkuat serbuk besi, mengungkapkan bahwa: densitas rata-rata pada penambahan fraksi Fe 5\%, 10\%, dan 15\% berturut-turut pada temperatur penuangan $70{ }^{\circ} \mathrm{C}$ sebesar $2.626 \mathrm{gr} / \mathrm{cm}^{3}, 2.563 \mathrm{gr} / \mathrm{cm}^{3}$, dan $2.579 \mathrm{gr} / \mathrm{cm}^{3}$. Densitas rata-rata pada penambahan fraksi Fe 5\%, 10\%, dan 15\% berturut-turut pada temperatur penuangan $725^{\circ} \mathrm{C}$ sebesar $2.697 \mathrm{gr} / \mathrm{cm}^{3}, 2.561 \mathrm{gr} / \mathrm{cm}^{3}$, dan $2.467 \mathrm{gr} / \mathrm{cm}^{3}$. Densitas rata-rata pada penambahan fraksi Fe 5\%, 10\%, dan 15\% berturut-turut pada temperatur penuangan $750^{\circ} \mathrm{C}$ sebesar $2.671 \mathrm{gr} / \mathrm{cm}^{3}, 2.517 \mathrm{gr} / \mathrm{cm}^{3}$, dan $2.675 \mathrm{gr} / \mathrm{cm}^{3}$. Porositas rata-rata pada penambahan fraksi Fe 5\%, 10\%, dan 15\% berturut-turut pada temperatur penuangan $700^{\circ} \mathrm{C}$ sebesar $0,112 \%, 0,184 \%, 0,232 \%$. Porositas rata-rata pada penambahan fraksi Fe 5\%, 10\%, dan 15\% berturut-turut pada temperatur penuangan $725^{\circ} \mathrm{C}$ sebesar $0,086 \%, 0,184 \%, 0,266 \%$. Porositas ratarata pada penambahan fraksi Fe 5\%,10\%, dan $15 \%$ berturut-turut pada temperatur penuangan $750^{\circ} \mathrm{C}$ sebesar $0,0958 \%$, 0,1985\%, 0,2038\%.

Tujuan penelitian ini adalah untuk mengetahui pengaruh paduan serbuk $\mathrm{Fe} 12 \%$ pada aluminium terhadap porositas dan struktur mikro dengan metode gravity casting.

\section{METODE PENELITIAN}

\section{A. Bahan Penelitian}

Bahan baku pengecoran yang digunakan scrap aluminium atau aluminium bekas dan serbuk besi tatal besi tuang hasil proses permesinan yang diperoleh dari industri pengecoran logam Batur, Ceper, Klaten

\section{B. Alat Penelitian}

Alat yang digunakan antara lain: Dapur peleburan krusibel, Pasir Cetak, Tetes tebu, Semen Portland, Pola. 
Jurnal ENGINE Vol.1 No.1, Mei 2017, pp 20-25

e-ISSN: 2579-7433

Ladel/Kowi milik lab pengecoran UP'45, Rangka Cetak, Timbangan berat, Mesin Uji Komposisi Kimia Spektrometer, Mikroskop optic, Blower, kokas, Arang kayu, Gergaji tangan, Resin.

\section{Tahapan Penelitian}

1) Pembuatan Pola dan Cetakan.

Pola dibuat dari kayu dengan bentuk disajikan pada Gambar 1.
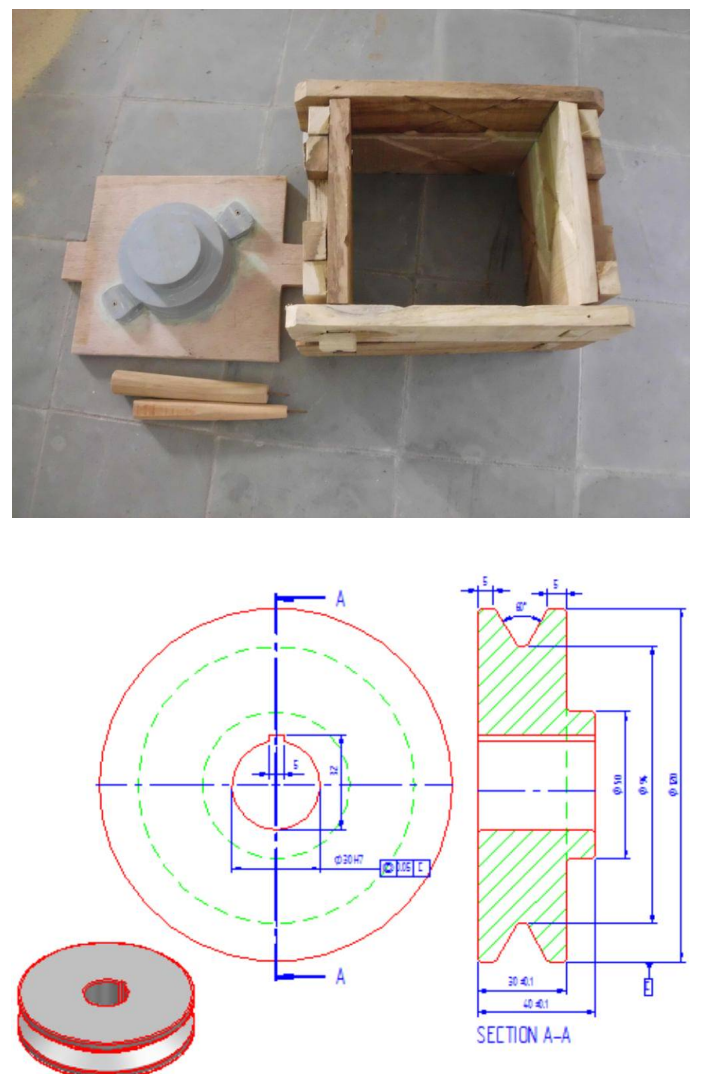

Gambar 1. Pola (ukuran mm)

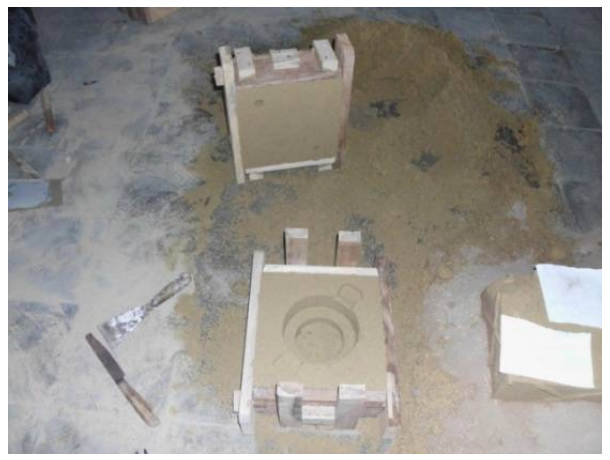

Gambar 2. Cetakan Pasir

2) Peleburan

Proses peleburan dilakukan di Laboratorium pengecoran logam Prodi Teknik Mesin Universitas Proklamasi 45 Yogyakarta. Alat untuk proses peleburan ini menggunakan dapur krusibel, seperti disajikan pada Gambar 2. Peleburan menggunakan dapur krusibel dengan bahan bakar kokas, yang di atasnya ditaruh kowi untuk tempat aluminium dan serbuk besi yang akan dilebur. Aluminium dan serbuk besi $12 \%$ ditimbang disesuaikan dengan volume dari pola, sehingga peleburan tidak mengalami kekurangan cairan logam aluminium.

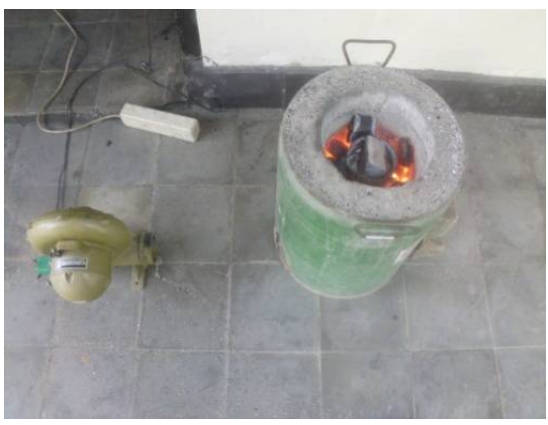

Gambar 3. Dapur Peleburan

\section{3) Pengamatan Porositas}

Pengamatan porositas dilakukan dengan melihat secara visual pada setiap sisi bagian luar dari benda coran. Dari ketiga spesimen benda coran tersebut di cari rata-rata porositas untuk menentukan tingkat porositas dari benda coran. Penentuan porositas menggunakan persamaan: massa jenis $=$ berat benda coran dibagi luas penampang benda coran atau $\left(\rho=\frac{m}{v}\right)$. Pengujian densitas dilakukan dengan menggunakan metode Archimedes. Porositas dapat didefinisikan sebagai perbandingan antara jumlah volume ruang kosong (rongga pori) yang dimiliki oleh zat padat terhadap jumlah dari volume zat padat itu sendiri. Porositas suatu bahan pada umumnya dinyatakan sebagai porositas terbuka atau apparent porosity, dan dapat dinyatakan dengan persamaan : 
Jurnal ENGINE Vol.1 No.1, Mei 2017, pp 20-25

e-ISSN: 2579-7433

$$
\text { Porosity }=1-\frac{\rho_{m}}{\rho_{t h}}
$$

keterangan:

$\boldsymbol{\rho}_{\mathrm{m}}:$ densitas aktual (gram/cm3)

$\boldsymbol{\rho}_{\text {th }}:$ densitas teoritis (gram/cm3)

\section{4) Pengamatan Struktur Mikro}

Pengamatan struktur mikro menggunakan mikroskop optik dilakukan dengan cara mengambil tiga sampel spesimen benda coran yang telah di preparasi mesin poles dan etsa.

\section{HASIL DAN PEMBAHASAN}

Hasil uji komposisi kimia benda coran bahan baku scrap aluminium ditunjukan Tabel 1, sebagai berikut:

Tabel 1. Komposisi kimia benda coran \begin{tabular}{|c|c|c|c|c|c|c|c|c|c|c|c|c|}
\hline Unsur & Al & Si & Fe & Mn & Mg & Cr & Ni & Zn & Sn & Ti & Pb & Zr \\
\hline \%komp & 78,13 & 3,83 & 12,0 & 0,225 & 2,99 & 0,25 & 0,125 & 0,167 & 0,518 & 0,577 & 0,248 & 0,789 \\
\hline
\end{tabular}

Unsur utama pembentuk benda coran yaitu aluminium, silikon, ferro, magnesium. Unsur Fe mempengaruhi aluminium menjadi lebih keras, unsur $\mathrm{Si}$ menyebabkan efek fluiditas baik. Hasil benda coran di sajikan Gambar 4 di bawah ini:

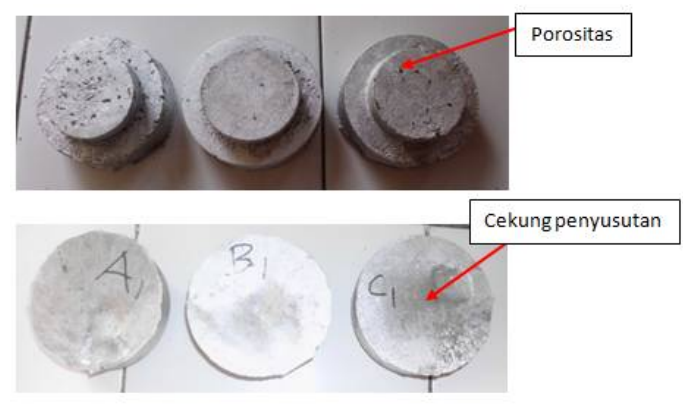

Gambar 4. Benda Hasil Coran

Benda coran secara umum mengalami porositas dan penyusutan, terutama pada bagian permukaan benda yang atas. Porositas terjadi karena terak yang ikut dalam logam cair dan membeku bersamasama logam cair. Porositas juga terjadi karena adanya gas hydrogen yang terjebak didalam logam cair tidak bisa keluar melalui pori-pori pasir cetak. Penyusutan logam cair aluminium setelah membeku cukup besar yaitu sekitar $6-10 \%$ hal ini membuat ukuran benda coran jadi kurang akurat. Penyusutan aluminium bisa juga disebabkan pengaruh dari aliran turbulensi cairan logam. Aliran turbulensi menyebabkan putaran logam cair sehingga pada bagian tengah terjadi kekosongan. Karena bagian tengah kosong maka pada saat logam cair membeku akan bergerak turun mengisi kekosongan tersebut.

\section{A. Pengaruh Dimensi Saluran Masuk terhadap Porositas.}

Pengaruh diameter saluran tuang terhadap porosiats ditunjukan Gambar 5 sebagai berikut:

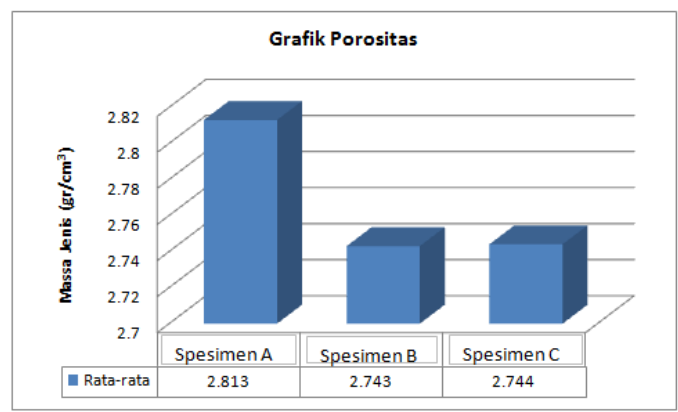

Gambar 5. Grafik porositas

Untuk menentukan porositas dalam penelitian ini menggunakan metode yaitu mencari volume benda coran (volume dalam $\mathrm{cm}^{3}$ ) dan menimbang benda coran (massa dalam gram). Dari kedua variabel tersebut kemudian dicari massa jenis yaitu dengan cara massa benda coran dibagi volume benda coran. Dari grafik 5 diperoleh nilai massa jenis yang berbedabeda, hal ini menunjukan bahwa porositas untuk masing-masing benda coran berbeda-beda. Nilai massa jenis benda coran rendah menunjukan tingkat porositas banyak atau lebih luas sebaliknya benda coran dengan nilai massa jenis tinggi menunjukan tingkat porositas sedikit. Dari grafik 5 tingkat porositas tertinggi diperoleh pada benda coran dengan dimensi saluran masuk spesimen $\mathrm{C}$ yaitu $2.743 \mathrm{gr} / \mathrm{cm}^{3}$ hal ini disebabkan oleh 
Jurnal ENGINE Vol.1 No.1, Mei 2017, pp 20-25

e-ISSN: 2579-7433

adanya aliran logam cair yang melewati saluran tuang cukup besar sehingga volume yang masuk tidak sesuai dengan rongga cetakan. Dengan dimensi saluran masuk yang lebih besar menyebabkan kecepatan aliran logam cair menjadi lebih cepat sehingga menyebabkan terjadi turbulen dan logam cair tidak dapat mengalir dengan sempurna. Sedangkan tingkat porositas yang rendah diperoleh pada diameter saluran masuk spesimen A yaitu $2.831 \mathrm{gr} / \mathrm{cm}^{3}$ ini sesuai dengan literatur yang diperoleh sebelumnya. Kesesuaian antara volume rongga cetak dengan dimensi saluran masuk menyebabkan aliran logam cair pada saat penuangan stabil sehingga logam cair mampu mengalir ke segala rongga cetakan dengan baik.

\section{B. Pengaruh Dimensi Saluran Masuk terhadap Struktur Mikro.}

Hasil foto struktur mikro pembesaran 200x dari benda coran spesimen A ditunjukan Gambar 6 sebagai berikut:

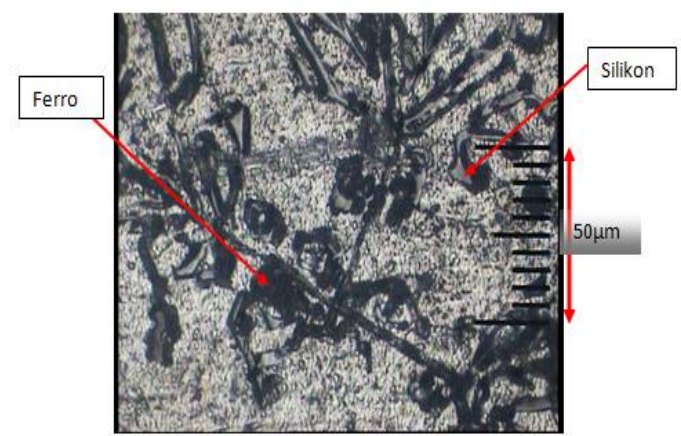

Gambar 6 Foto struktur mikro spesimen A pembesaran $200 \mathrm{X}$

Komposisi Al78,13\% + $\mathrm{Fe} 12 \%+\mathrm{Si} 3$, $83 \%+\mathrm{Mg} 2,99 \%$ berdasarkan referensi mendekati $\mathrm{Al}$ alloy dengan paduan $\mathrm{Si}+\mathrm{Mg}$ termasuk seri 5xxx. Penyebaran unsur Fe tidak merata, Si bersenyawa dengan $\mathrm{Fe}$ sedangkan $\mathrm{Mg}$ tersebar bersenyawa dengan Aluminium. spesimen A pada saat penuangan logam cair kedalam cetakan membutuhkan waktu yang paling lama, karena dimensi lubang paling kecil. Hal ini menyebabkan pembekuan logam secara baik dan struktur Kristal tersusun sesuai sifatnya.

Hasil foto struktur mikro spesimen B disajikan Gambar 7 di bawah ini:

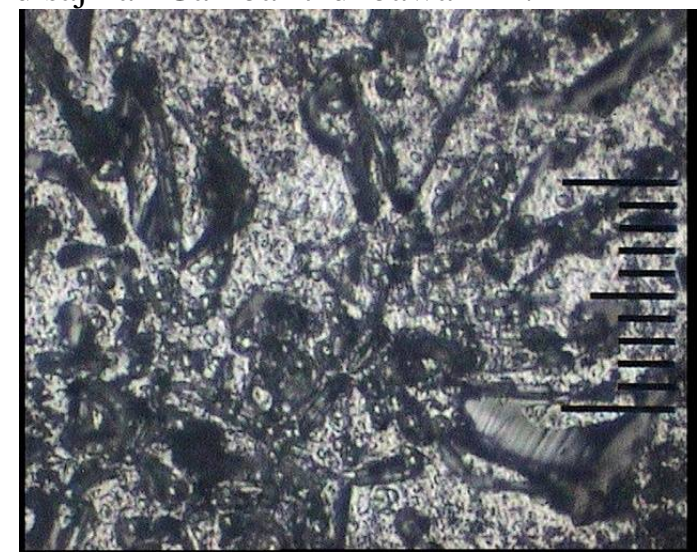

Gambar 7 Foto struktur mikro spesimen B pembesaran $200 \mathrm{X}$

Foto Struktur mikro spesimen B menunjukan bahwa penyebaran $\mathrm{Fe}$ dan Silikon lebih merata hal disebabkan oleh pemenuhan ruang cetakan yang lebih cepat dan pembekuan logam cair juga lebih cepat. Pembekuan cepat membuat Kristalkristal dari logam belum sempat tersusun dengan sempurna, karena lebih dulu membeku. Hasil foto struktur mikro spesimen $\mathrm{C}$ ditunjukan Gambar 8 di bawah ini:

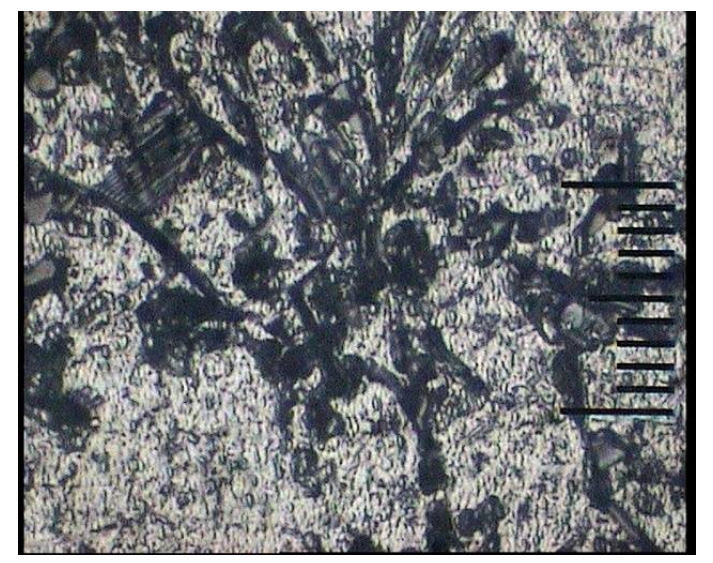

Gambar 8. Foto struktur mikro spesimen C pembesaran 200X

Dari Gambar 8 menunjukan bahwa foto struktur mikro spesimen $\mathrm{C}$ hampir sama dengan foto struktur mikro spesimen A. Antara $\mathrm{Fe}$ dan silikon bersenyawa, 
Jurnal ENGINE Vol.1 No.1, Mei 2017, pp 20-25

e-ISSN: 2579-7433

sedangkan Aluminium dan $\mathrm{Mg}$ bersenyawa. Ini menunjukan konsistensi persenyawaan antara unsur-unsur yang ada dalam logam tersebut.

\section{KESIMPULAN}

a. Pengaruh paduan $\mathrm{Fe} 12 \%$ terhadap porositas adalah rata - rata porositas yang terjadi pada spesimen A, B dan C sebesar 2,766 gr/ $\mathrm{cm}^{3}$

b. Pengaruh paduan $\mathrm{Fe} 12 \%$ terhadap struktur mikro adalah terjadi penyebaran unsur $\mathrm{Fe}, \mathrm{Si}$ dan $\mathrm{Mg}$ secara merata tetapi untuk spesimen $\mathrm{C}$ unsur $\mathrm{Fe}$ dan $\mathrm{Si}$ bersenyawa sedangkan unsur $\mathrm{Al}$ dan $\mathrm{Mg}$ bersenyawa secara terpisah.

\section{DAFTAR PUSTAKA}

Ashar, L.H., dkk (2012), “Analisis Pengaruh Model Sistem Saluran dengan Pola Styrofoam terhadap Sifat Fisi dan Kekerasan Produk Puli pada Proses Pengecoran Aluminium Daur Ulang". Jurnal Momentum, Vol. 8, No. 1, April 2012

ASM Handbook, 2004, "Metallography and Microstructures, Volume 8.

ASM Handbook, 2004, "Mechanical Testing and Evaluation, Volume 9.

Brown, J.R. (editor), 2000, "Foseco Ferrous Foundryman's Handbook", Butter worth -Heinenman, Great Britain.

Callister, W.D., 2007, "Materials Science and Engineering", 7th ed., John Wiley and Sons, USA.

Campbell, J., 2003, "Casting", 2nd ed., Butterworth-Heinemann..
Science", 11th ed., Satya Prakashan, India.

Mahendra, R., dkk (2012), "Studi Eksperimen Pengaruh Jenis Saluran pada Aluminium Sand Casting terhadap Porositas Produk Toroidal Piston" Jurnal Teknik Mesin ITS Vol. 1, No. 1, 2012. ISSN: 2301-9271

Praestya, C., dkk (2012), "Pengaruh Jumlah Saluran Masuk pada Pengecoran Impeller Turbin Croosflow terhadap Cacat Permukaan dan Porositas" Jurnal Teknik Mesin, Universitas Brawijaya Malang.

Surdia, T dan Chijiwa, K, 1996, "Teknik Pengecoran Logam", Cetakan ke tujuh, ISBN 979-408085-3, PT. Pradnya Paramita, Jakarta.

Stefanescu, D.M., 2009, "Science and Engineering of Casting Solidification", 2nd ed., Springer Science+Business Media, New York.

Surdia, T. dan Chijiwa, K., 2006, “Teknik Pengecoran Logam", P.T.Pradnya Paramita, Jakarta.

www.twi.co.uk/content/jk74.hmtl,17

Maret 2012

www.hapli.files.worldpress.com, 24- Juni2012

Gupta, R.B., 2002, "Material 